\title{
A brief review of current orthopedic implant device issues: biomechanics and biocompatibility
}

\section{Patrick Hannon* \\ Department of Biology, Northern Arizona University, USA}

The improvement of bone fixation and joint replacement hardware has been an evolutionary process involving a team approach with biomechanists, physicians, and mechanical/materials engineers. Biomaterials in orthopedics or dentistry require that the implant material be very resistant to repeated stresses and metals, ceramics, and some composites meet this requirement. Improvements in joint replacement polyethylene components have also become more durable with reduced penetration by incorporating highly cross-linked polyethylene into the articulating surfaces [1]. The complexity of the development of these hardware devices lies in factors and problems relating to: 1) biocompatibility 2) the use of modular components in joint replacements for an improved custom fit and 3) the failure of the bone fixation due to stress shielding of the underlying bone.

\section{Biocompatibility}

Biocompatibility is an increased concern in joint replacements where fretting may potentially contribute to an increase of the migration of metal ions as well as fatigue failure of the implanted device over time. However, biocompatibility is still a concern in bone fracture/defect fixation due to the possible toxicity of metal implant components. Metal implants exhibiting a degree of biological tissue toxicity such as cobalt-chromium alloys are still used in joint implants because of their resistance to shear stresses and reduced surface fretting in joint replacements. Yet, cobalt-chromium alloys have been found to be toxic to surrounding biological tissues at high levels in a small number of patients (i.e., cobalt mean of $6.0 \mathrm{ng} / \mathrm{ml}$ and chromium mean of $0.6 \mathrm{ng} / \mathrm{ml}$ ) when used in a cobalt-chromium alloy femoral neck stem joined to the modular femoral head of the implant at the acetabulum (i.e., hip socket) [2]. Metal alloys containing nickel or aluminum although corrosion resistant and low in mass relative to volume have been found to be toxic and may result in inflammation of laminar bone and surrounding soft tissues. For example, an accumulation of aluminum but not titanium was found in soft tissues and newly formed bone lamella surrounding titanium plates affixed to human maxillae of the face with the use of Ti6Al4V titanium alloy bone screws (a titanium alloy with $6 \%$ aluminum and $4 \%$ vanadium) [3]. Furthermore, the titanium alloy Ti6Al4V (i.e., Ti-64) is in widespread use in orthopedic joint and bone fixation plate/rod implants and is very corrosion resistant, exhibits a high tensile strength $(860 \mathrm{MPa})$ in addition to exhibiting high stiffness with a Young's modulus of 114-120 GPa [4,5]. However, vanadium which is $4 \%$ of Ti- 64 has also raised some concern regarding its cytotoxicity and new alloys which substitute vanadium for a small percentage of iron (Ti-5Al-2.5FE) or niobium (Ti6Al-7Nb) address these concerns [4]. New strong titanium alloys with metals

${ }^{1}$ Galvanic corrosion has long been known to occur when dissimilar metals of screws, plates or rods come together in the presence of body tissue fluids (electrolytes) to form an electrical (galvanic) couple. including molybdenum and niobium have been found to be non-toxic at levels of 8.5 and 172.0 microg/L respectively, [6] and furthermore reduce stress shielding in orthopedic implants.

\section{Use of modular implant components}

Some surgeons prefer to use joint implant assembled components because they can better match the patient's anatomy and address several other factors. An example is a hip joint replacement where the surgeon would like to match the angle of the femoral neck to the long bone shaft of the contralateral non-surgical side and/or correct for a discrepancy in left vs. right lower extremity length. Additionally, a more acute angle at the implanted femoral neck-long shaft junction results in a longer moment arm for the hip abductor musculature and therefore increased $\mathrm{ft}-\mathrm{lbs}$ of moment for post-operative abduction strength in the patient. However, sometimes individual modular components will make use of different metal alloys because each alloy serves a different purpose to maximize bone fixation, resisting long bone re-fracture and reducing friction/adhesion characteristics of the moveable joint bearing in joint replacements. An example is when a surgeon during a total hip replacement uses a femoral shaft medullary canal stem of titanium (Ti-64), a cobalt-chromium neck, and a ceramic or cobalt-chromiummolybdenum (CoCr-Mo) ball head (fitted into the hip socket) [7].

One problem with joint replacements making use of metal component systems is that the junctions between components may result in significant fretting over time due to implant component micro movement with the consequent production of metal debris. Additionally, dissimilar composition of metal components may raise a concern of galvanic corrosion of the implant and increased migration of metal ions into soft tissues and/or bone ${ }^{1}$.

\section{Reducing stress shielding in bone}

Ti-64 alloy exhibits high stiffness which due to stress shielding can result in bone atrophy/degradation resulting in a failed implant interface with time. New titanium alloys which may include iron (FE), niobium $(\mathrm{Nb})$, molybdenum $(\mathrm{Mo})$ or tin $(\mathrm{Sn})$ act to reduce the stiffness of an orthopedic implant to more closely approximate the Young's Modulus of cortical bone (i.e., approximately $20 \mathrm{GPa}$ ). Titanium alloy implants incorporating such metals are less stiff with a Young's Modulus of 50-70 GPa and therefore more closely approximate the

Correspondence to: Dr. Patrick Hannon, Retired Professor and Emeritus Faculty, Northern Arizona University- Department of Biology, USA; E-mail: Hannon@hannonbiomechanics.com

Received: November 05, 2016; Accepted: November 21, 2016; Published: November 24, 2016 
stiffness of the underlying cortical bone enabling the implant to better transfer the loads of daily human activity to the bone. In accord with Wolff's law, this transfer of repeated significant loads to bone tissue results in maintaining the structural and functional integrity of both spongy and cortical (laminar) bone and therefore better maintains the implant interface over the longer term extending or eliminating the need for a surgical implant revision. Other factors such as the length of the long bone stem in TKA/THA joint replacements (i.e., affect upon stress shielding) or using cemented $\mathrm{v}$. non-cemented components in joint replacements may affect the long-term outcome in specific patients. Biological individuality including factors such as gender, regional bone density/muscle density, age and general health can all affect the surgeon's choice of orthopedic hardware and method of fixation $[1,8-10]$.

Joint replacements are increasingly being developed for new body regions and fracture fixation plating, intramedullary rod fixation (long bones) has improved with changes in geometry and implant material to reduce stress shielding. Plates and cages sometimes remain in the body over the human life span, some are removed later and some implants are now biodegradable (over a predictable time) eliminating the necessity of future removal [11].

\section{References}

1. Digas G (2005) New polymer materials in total hip arthroplasty. Evaluation with radiostereometry, bone desitometry, radiography and clinical parameters. Acta Orthop Suppl. 76: 3-82. [Crossref]
2. Cooper HJ, Urban RM, Wixson RL, Meneghini RM, Jacobs JJ (2013) Adverse local tissue reaction arising from corrosion at the femoral neck-body junction in dual-taper stem with a cobalt-chromium modular neck. The Journal of Bone and Joint Surgery 95: 865-872. [Crossref]

3. Zaffe D, Bertoldi C, Consolo U (2004) Accumulation of aluminum in lamellar bone after implantation of titanium plates, Ti-6AL-4V screws, hydroxyapatite granules. Biomaterials, 17: 3837-3844. [Crossref]

4. Sidambe A (2014) Biocompatibility of advanced manufactured titanium implants--A review. Materials, 7: 8168-8188.

5. Tanaka H, Mori Y, Noro A, Kogure A, Kamimura M, et al. (2016) Apatite formation and biocompatibility of a low Young's Modulus Ti-Nb-Sn alloy treated with anodic oxidation and hot water. PLoS One 11: e0150081. [Crossref]

6. Li Y, Wong C, Xiong J, Hodgson P, Wen C (2010) Cytotoxicity of titanium and titanium alloying elements. J Dental Research 89: 493-497. [Crossref]

7. Krishnan H, Krishnan SP, Blunn G, Skinner JA, Hart AJ (2013) Modular neck femoral stems. Bone Joint J 95B: 1011-1021. [Crossref]

8. Gargiulo P, Pétursson T, Magnússon B, Bifulco P, Cesarelli M (2013) Assessment of total hip arthroplasty by means of computed tomography 3D models and fracture risk evaluation. Artif Organs. 37: 567-573. [Crossref]

9. Gargiulo P, Helgason T, Ramon C, Jr Jonhson H, Carraro U (2014) CT and MR Assessment and Characterization Using Segmentation and 3D Modeling -Techniques: Applications to Muscle, Bone and Brain. Eur J Transl Myol 24: 3298. [Crossref]

10. Pétursson P, Edmunds KJ, Gíslason MK, Magnússon B, Magnúsdóttir G, et al. (2015) Bone Mineral Density and Fracture Risk Assessment to Optimize Prosthesis Selection in Total Hip Replacement. Comput Math Methods Med 162481.

11. Park H, Temenoff J, Mikos A (2007) Biodegradable Orthopedic Implants in Engineering of Functional Skeletal Tissues, Bronner, F, Farach-Carson, M. and Mikos, A. (Eds.) Springer Publishing.

Copyright: (C)2016 Hannon P. This is an open-access article distributed under the terms of the Creative Commons Attribution License, which permits unrestricted use, distribution, and reproduction in any medium, provided the original author and source are credited. 